\title{
Using technology to encourage student engagement with feedback: a literature review
}

Stuart Hepplestone*, Graham Holden, Brian Irwin, Helen J. Parkin and

Louise Thorpe

Student and Learning Services, Sheffield Hallam University, Sheffield, UK

(Received 8 November 2010; final version received 13 April 2011)

\begin{abstract}
This article presents a review of the literature over the past 10 years into the use of technological interventions that tutors might use to encourage students to engage with and action the feedback that they receive on their assessment tasks. The authors hypothesise that technology has the potential to enhance student engagement with feedback. During the literature review, a particular emphasis was placed on investigating how students might better use feedback when it is published online. This includes where an adaptive release technique is applied requiring students to submit an action plan based on their feedback to activate the release of their grade, and electronic generation of feedback using statement banks. Key journals were identified and a snowball technique was used to select relevant literature. The use of technology to support and enhance student learning and assessment is well documented in the literature, and effective feedback practices are similarly well published. However, in terms of the use of technology to support and enhance feedback processes and practices (i.e. production, publication, delivery and students making use of feedback through technology), we found the literature to be limited.
\end{abstract}

Keywords: engagement; feedback; technology

\section{Introduction}

Feedback on assessments is an integral feature of effective and efficient teaching and learning, and can be one of the most powerful ways in which to enhance and strengthen student learning (Black and Wiliam 1998; Sadler 2010). Price et al. $(2010,277)$ argue that feedback is "the most important part of the assessment process". Feedback enables learning by providing information that can be used to improve and enhance future performance. This paper explores current literature around the appropriate use of technology in the production and delivery of feedback. It was anticipated that the literature would support the hypothesis that technology has the potential to enhance student engagement with feedback. ${ }^{1}$

Models, principles and conditions that support good feedback practice have been proposed (for example, Gibbs and Simpson 2004; McDowell et al. 2005; Nicol and Macfarlane-Dick 2006). For feedback to be effective and attended to by students, it needs to be timely (i.e. while it matters to them and useful for future assessments), legible, and aligned with explicit assessment criteria, as emphasised by Nicol (2009,

*Corresponding author. Email: s.j.hepplestone@shu.ac.uk 
337): "Feedback should be of sufficient quantity; timely; it should focus on learning not marks; it should be related to assessment criteria and be understandable, attended to and actually used by students to make improvements on their work". Appropriate use of learning technologies can encourage better engagement with feedback.

Despite the promotion of good feedback, much of the practice reported tends to focus on the ineffectiveness of feedback (Bloxham and Boyd 2007; Hounsell 2008; Rowe and Wood 2007; Rust, O'Donovan, and Price 2005). Pressures in the UK higher education sector (Department for Education and Skills 2003) resulting in modularisation and semesterisation have seen the bunching of assessment tasks toward the end of the module. This not only limits the scope for feedback practices that feed forward into future assessments (Higgins, Hartley, and Skelton 2002; Irons 2008; Price and O’Donovan 2008; Yorke 2001), but also into their professional practice (Poulos and Mahony 2007). These pressures have also seen the writing of feedback under increasingly tight time constraints (Chanock 2000). The result has been a negative impact on the student experience of feedback as supported by responses to the National Student Survey (Higher Education Funding Council for England 2007). Students have expressed dissatisfaction with the adequacy of the feedback they receive both in terms of timing and usefulness (Mutch 2003; Price et al. 2010). This is echoed further by large-scale (Hounsell and Entwistle 2007) and small-scale (Crook, Gross, and Dymott 2006) studies into the student experience of assessment and feedback.

Staff complain that feedback does not work (Weaver 2006) and that students do not act on feedback (Mutch 2003). It is claimed that students are only concerned with their grades (Wojtas 1998; Nesbit and Burton 2006), see feedback as a means to justify the grade (Price and O'Donovan 2008; Price et al. 2010) or only read the qualitative comments if the quantitative mark is outside of their expectations (Duncan 2007). Some authors have argued that student disengagement with feedback is based on sceptical or anecdotal evidence from tutors (Carless 2006; Higgins, Hartley, and Skelton 2002; Weaver 2006), and Burke $(2009,41)$ wonders whether "students interpret the term 'feedback' literally and use it only to look back on work they have completed, and are not aware or able to use tutor comments to 'feed-forward' and contribute to their ongoing development". In addition, Maclellan $(2001,316)$ suggests that use of 'implicit criteria' by tutors means that students do not view feedback on their learning as helpful, and Bloxham and Boyd (2007) and Higgins, Hartley, and Skelton (2002) point to difficulties for students in deciphering handwritten feedback comments as a further reason why students do not read or make use of their tutors' comments.

There is a growing body of research exploring how technology might be used to support effective and efficient feedback practices. Nicol (2009) explains the aims of the Re-Engineering Assessment Practices in Scottish Education project and demonstrates the ways in which technology can be used to support the development of self-regulation, the organisation of assessment tasks and the provision of feedback in large (150-900 students) first-year classes, where modularisation and larger student numbers have reduced formative assessment and feedback opportunities.

\section{Approach}

This article builds on an earlier literature review undertaken and made available via a wiki by the authors in 2008/09 in preparation for a research project to explore 
how students at Sheffield Hallam University engage with feedback delivered electronically when three specific technological interventions are used. The research project (Parkin et al. forthcoming) aimed to find out how students might engage with feedback and formulate actions to improve future learning when:

feedback and grades are published online;

feedback is published online without the grade and using an adaptive release process whereby students are encouraged to reflect on and submit an action plan based on their feedback to activate the release of the grade; and

feedback is produced via electronic comment banks aligned to the original assessment criteria and presented in a table or grid format.

In this article, recent studies are considered alongside the previous literature in providing an up-to-date review of the technological interventions that might encourage student engagement with feedback.

A literature search was undertaken using the terms 'technology', 'feedback' and 'engagement' across electronic catalogues and search engines. In addition, the contents of the Association for Learning Technology's Journal, Research in Learning Technology, Assessment \& Evaluation in Higher Education and British Journal of Educational Technology (identified as being three of the key journals with a focus on the use of educational technology and assessment in higher education) were browsed from 2001, as well as relevant conference proceedings including the Association for Learning Technology's Conference and the International ComputerAssisted Assessment Conference. Articles were selected based on both the title of the paper and its abstract, and we used the 'snowball' technique to identify additional sources from references within the articles.

Our focus is on the production, delivery and the process for making use of that feedback rather than the format of the feedback itself. We were particularly interested in research and discussion that explored the publication of feedback and grades online, the automated adaptive release of grades (or how technology can support encouraging student engagement through disengaging the grade from feedback), and the use of technology to automatically generate feedback aligned to assessment criteria through pre-populated statement banks.

This literature review aims to address the comment by Burke $(2009,42)$ in which the author claims "it appears that we currently have a blind spot in relation to strategies for students making effective use of feedback" and supports Whitelock (2009, 199):

e-Assessment has the potential to offer new forms of assessment with immediate feedback to students ... It is therefore becoming increasingly important to construct a pedagogically driven model for e-assessment that can incorporate e-assessment and e-feedback into a holistic dialogue learning framework, which recognises the importance of students reflecting upon and taking control of their own learning.

\section{Findings}

Our findings have been presented within the technological interventions identified in the approach. Two additional sections have also been included regarding the use of technology to encourage student engagement with feedback as there are a wide range of articles focused on the use of computer-assisted assessment with instant 
feedback and a growing use of peer assessment supported by electronic or online tools. It felt worth capturing this wealth of literature.

\section{Using technology to publish feedback}

Sending tutors' comments electronically (Bloxham and Boyd 2007; Crossouard and Pryor 2009; Denton 2001a, 2001b, 2003; Denton et al. 2008; Gipps 2005; Irons 2008 ) is an effective and simple means of communicating formative feedback to students, and can enhance the way in which students receive and engage with feedback. This may be feedback on an individual or group piece of work, or feedback generic to an entire student cohort on a module. Students can receive their feedback in privacy, enabling them to respond to their feedback in different ways and at different times (Price and O'Donovan 2008). A number of other studies have reported on the greater impact of electronic or online feedback (Van den Boom et al. 2004; Guardado and Shi 2007; Tuzi 2004).

Price and O'Donovan (2008) argued that feedback should be incorporated into the learning and teaching process both to improve student engagement with feedback and to enable the effectiveness to be measured. Maclellan (2001) argued that students should be monitoring their own performance in order to make effective use of feedback to generate improvement in learning, and this has been supported by Carless (2006, 229) who suggested that students should be provided with the "means to distinguish accurately their achievements in different assignments". Fulda (2005) reports on US colleges and universities mandating that grades be entered online. Not only does this offer cost and efficiency savings in transcribing grades and reducing the risk of error, the same interface can be made available to students allowing them quicker access to their grades.

\section{Producing feedback electronically}

Examples of producing feedback electronically include the use of 'Track Changes' and 'Comments' in Microsoft Word to alter and annotate the student's original word-processed work (Crossouard and Pryor 2009), and comments typed in a separate document or digital ink using a tablet PC (Plimmer and Mason 2006) providing individual feedback on student work. Heinrich et al. (2009) reported on the use of technology in the context of managing and marking assignments for a large student cohort. It was claimed that the real impact of technology is in administration efficiencies (e.g. documents are easily accessible to all involved in the marking process any time and any place). As such this frees up time for focusing on producing quality, more detailed and legible feedback, with the option to provide direct links to further online resources, articles and books.

Recent practice and studies have focused on the development of systematic methods to produce and return feedback that has been mapped against predefined assessment criteria or learning outcomes (Irons 2008; Sadler 2010). The use of Microsoft Office applications, templates and the computer-supported generation of individualised feedback documents from statement or question response banks have been developed to improve quality in response to increased student numbers (Denton 2001a, 2001b, 2003; Denton et al. 2008; Heinrich et al. 2009; Hepplestone and Mather 2007; Irons, 2008). Hornby (2005) reports on the use of checklists and statement banks to automate the feedback process using a criterion reference 
scheme in which grade related statements were generated and cut-and-pasted into a personalised feedback report for each student and returned electronically.

A recent innovation is the use of audio feedback (Middleton 2009), although to date studies and practice have remained small-scale despite personal recording devices being readily available and recording software relatively easy to use. In a recent study by Rodway-Dyer, Dunne, and Newcombe (2009) of first-year students receiving audio feedback, they found that the main advantage was the greater detail and depth of information offered, as well as removing misunderstandings due to illegible handwriting. A major disadvantage of the approach is that it often separates the assignment and feedback with loss of annotations (Ribchester, France, and Wheeler 2007), making it difficult for students to identify the point in their work being discussed (Rodway-Dyer, Dunne, and Newcombe 2009). Rotheram (2009) advocates the use of audio feedback, claiming that students have the advantage of replaying feedback, although Rodway-Dyer, Dunne, and Newcombe (2009) found no evidence to suggest that students will no more listen repeatedly to audio feedback than they would re-read written feedback. Merry and Orsmond (2008) found that all students listened to the feedback with a copy of their submitted work in front of them at least once, with the majority of students altering their work as they listened to the feedback. In a further study of first-year and third-year students by Ribchester, France, and Wheeler (2007) it was found that the length of the recording may impact on student engagement: the first-year students had a natural listening threshold of around five minutes while the third-year students listened to the whole recording. Despite claims by Merry and Osmond (2008) and Rotheram (2009) that audio files are easy to store, and the findings by Ribchester, France, and Wheeler (2007) that students accessed the feedback off-campus, there was a reluctance by students to store feedback on personal devices (Ribchester, France, and Wheeler 2007).

\section{Adaptive release of grades}

We were interested in how technology might be used to encourage students to engage with their feedback by initially providing feedback without the grades, and only revealing the grade once the student had completed a task to indicate that they had read, considered and sought the opportunity to use the feedback in their future learning. Although we were unable to find examples from the literature to support this practice through the use of technology, several authors have advocated that disengaging the grade or withholding the grade from feedback promotes student learning (for example, Boud and Falchikov 2006; Butler 1988; Carless 2006; Ecclestone and Swan 1999; Nicol 2007; Potts 1992; Rust, O’Donovan, and Price 2005). Such practice also reflects the view that feedback can only support learning if it involves the production of evidence or is built into personal development planning (for example, Bloxham and Boyd 2007; Draper 2009; Higgins, Hartley, and Skelton 2002; Irons 2008; Mutch 2003; Rust, O’Donovan, and Price 2005).

\section{Computer-assisted assessment}

Although not a focus of the original literature review, it was apparent that one of the most published uses of technology to provide students with formative feedback (or e-feedback) is through computer-based testing, quizzes or assessment using mul- 
tiple-choice or similar objective question types (Bull and McKenna 2004; Denton et al. 2008; Handley and Cox 2007). The purpose is to promote independent learning and enable students to monitor their progress and development by undertaking assessment tasks at a time and place of their choosing (Irons 2008). Challis (2005) promotes the opportunity computer-aided testing allows for students to effectively learn and explore areas of perceived weakness in privacy without the fear of revealing mistakes to peers or tutors, while Miller (2009) discusses the use of computerassisted assessment to provide feedback to improve student learning. Such tests are often made available as open access, essentially allowing students to repeat the assessment an unlimited number of times. However, despite their formative nature, the results of these tests may contribute towards a summative grade, and are therefore initially made available as a single attempt to generate the grade, and subsequently made openly available at the end of the module to aid revision. The use of commercial software products can deliver detailed formative feedback for each individual question, or specifically tailored to a particular response, more efficiently than is possible with traditional assessment (Brown, Bull, and Race 1999; Bull and McKenna 2004; Gipps 2005), and students favour the immediacy of such feedback as it keeps the activity and result closely connected, meaningful and current (Charman 1999; Denton et al. 2008). Peat and Franklin (2002) describe the development of various online computer-based assessment components (including the use of weekly quizzes, mock examinations and self-assessment modules) and how students respond to these changes, while Hornby (2005) discusses the efficiencies afforded by the use of automated computer assessment in allowing students to take control of their learning and self-assess. Computer-adaptive testing (Challis 2005; Conole and Warburton 2005; Irons 2008) can be used in order to match the formative assessment to the individual students' ability as well as setting benchmarks for students to attain before moving on to the next learning or assessment activity.

\section{Peer assessment}

Technological innovations and developments have been used to engage students in the process of peer assessment and peer feedback (Freeman and McKenzie 2002; Li, Liu, and Steckelberg 2010; Loddington et al. 2009). Both Freeman and McKenzie (2002) and Loddington et al. (2009) illustrate that the use of technology can improve the fairness of group assessment by acknowledging, rating and rewarding individual contributions and enhancing students' learning from team tasks, whereas Li, Liu, and Steckelberg (2010) found a significant relationship between the quality of the peer feedback the students provided for others and the quality of the students' own final projects.

\section{Conclusions}

This literature review found that there are a significant number of publications and articles that promote and suggest good feedback principles, models and practice. Similarly, a wide range of literature focuses on the belief that feedback practice in its present form does not work. In some cases the authors seek answers by criticising current structures in higher education (i.e. modularisation, large student numbers and time pressures) for feedback that does not feed forward into future modules or assignments. Also some literature seeks to blame students for focusing only on the 
grade, not seeing the connections between modules and assessments, or concentrating on feedback comments only when the grade does not meet their expectations for effort put into completing the assessment.

A growing number of studies support the hypothesis that technology has the potential to enhance student engagement with feedback, suggesting that changing the process by which feedback is made available to students can enhance student engagement with feedback. Feedback published online offers students a level of flexibility in being able to read it at a time convenient to them and concentrate more deeply on the comments in the absence of their peers. As the feedback is stored online, students are offered further convenience in accessing this information whenever and wherever they complete future assessments, and where available via a virtual learning environment, for example, the feedback can be used within the context of the rest of their learning. Where grades are aggregated alongside this feedback, students can use this quantitative information to inform their performance in future assessment tasks. There is further evidence to suggest that feedback returned electronically is timelier as time is saved during administrative processes.

Publishing feedback online can often require a change in the way feedback is produced. The use of typed comments on students' original work enables students to see legibly the areas requiring focus and attention. The use of electronic statement banks to generate feedback aligned to the original assessment criteria, often used to speed up the generation of feedback, enables students to view their strengths and weaknesses in a structured and cohesive way and use these to set future learning targets. The growing use of audio feedback enables tutors to provide more detailed feedback than traditional written methods, although it is important to consider that students' attention spans may diminish during listening to lengthy recordings. In using both statement banks and audio feedback, it is essential that any points raised are referred in some way back to the students' original work, otherwise the feedback may appear separate and unhelpful.

There is evidence that providing feedback without the grade encourages students to focus on the actual comments. We were interested in identifying methods used, in particular the use of technology, to encourage students to reflect on and develop action plans as a result of receiving their feedback without the grade, only receiving their grade after acting on their feedback. Although we could not find any evidence of the process being supported electronically, there were suggestions that student behaviour on making use of feedback could be changed through linking the process into personal development planning.

While reviewing the literature, two further uses of technology to support student engagement with feedback were identified. For some time it has been argued that the use of computer-assisted assessment can engage students by providing feedback instantly and is therefore closely connected with activity. Often students repeat the assessment without the fear of publicly revealing any inadequacies in their knowledge to peers and tutors. Providing students with access to such tests are increasingly popular through easy-to-use online assessment tools and within virtual learning environments. Peer-assessment and peer-feedback activities are increasingly making use of technology. It is claimed that by providing feedback on their peers' work (often anonymously), students are better equipped to engage with published assessment criteria and often make greater improvements on their own work as a result of giving feedback than from the feedback they receive themselves from their peers. 
As a result of conducting this review of the literature about the technological interventions that might encourage students to engage with their feedback, we realise that day-to-day effective assessment and feedback practice is rarely reported in the literature. It may be that practitioners do not see the value in what they do due to its proximity to their practice, and we feel that there is a need for day-to-day practice to be reported and celebrated. Often examples of good practice can be seen at conferences and small-scale internal events. Where it is published, there tends to be a focus on the problematic nature of assessment and feedback, rather than reporting on effective strategies as well as where the use of technology can support the production, delivery and student engagement with feedback.

\section{Note}

1. Please note, as a clarifying point this paper will use the term 'module' to mean an individual unit or course of study; and where quoted from third-party sources, the term 'marks' means 'grades'.

\section{References}

Black, P., and D. Wiliam. 1998. Assessment and classroom learning. Assessment in Education 5, no. 1: 7-74.

Bloxham, S., and P. Boyd. 2007. Developing effective assessment in higher education. Maidenhead: Open University Press.

Boud, D., and N. Falchikov. 2006. Aligning assessment with long-term learning. Assessment \& Evaluation in Higher Education 31, no. 4: 399-413.

Brown, S., J. Bull, and P. Race. 1999. Computer-assisted assessment in higher education. London: Kogan Page.

Bull, J., and C. McKenna. 2004. Blueprint for computer-assisted assessment. London: RoutledgeFalmer.

Burke, D. 2009. Strategies for using feedback students bring to higher education. Assessment \& Evaluation in Higher Education 34, no. 1: 41-50.

Butler, R. 1988. Enhancing and undermining intrinsic motivation: The effects of task-involving and ego-involving evaluation of interest and performance. British Journal of Educational Psychology 58, no. 4: 1-14.

Carless, D. 2006. Differing perceptions in the feedback process. Studies in Higher Education 21, no. 2: 219-33.

Challis, D. 2005. Committing to quality learning through adaptive online assessment. Assessment \& Evaluation in Higher Education 30, no. 5: 519-27.

Chanock, K. 2000. Comments on essays: Do students understand what tutors write? Teaching in Higher Education 5, no. 1: 95-105.

Charman, D. 1999. Issues and impacts of using computer-based assessments (CBAs) for formative assessment. In Computer assisted assessment in higher education, ed. S. Brown, J. Bull, and P. Race, 85-93. London: Kogan Page.

Conole, G., and B. Warburton. 2005. A review of computer-assisted assessment. ALT-J Research in Learning Technology 13, no. 1: 17-31.

Crook, C., H. Gross, and R. Dymott. 2006. Assessment relationships in higher education: The tension of process and practice. British Educational Research Journal 32, no. 1: 95-114.

Crossouard, B., and J. Pryor. 2009. Using email for formative assessment with professional doctorate students. Assessment \& Evaluation in Higher Education 34, no. 4: 377-88.

Denton, P. 2001a. Generating and e-mailing feedback to students using MS Office. In Proceedings of the 5th International Computer Assisted Assessment Conference, July 2-3, ed. M. Danson, 157-73. Loughborough: Learning and Teaching Development, Loughborough University.

Denton, P. 2001b. Generating coursework feedback for large groups of students using MS Excel and MS Word. University Chemistry Education 5, no. 1: 1-8. 
Denton, P. 2003. Returning feedback to students via email using Electronic Feedback 9. Learning and Teaching in Action 2, no. 1. http://www.celt.mmu.ac.uk/ltia/issue4/denton. shtml.

Denton, P., J. Madden, M. Roberts, and P. Rowe. 2008. Students' response to traditional and computer-assisted formative feedback: A comparative case study. British Journal of Educational Technology 39, no. 3: 486-500.

Department for Education and Skills. 2003. The future of higher education. Cm 5735. London: The Stationery Office.

Draper, S. 2009. What are learners actually regulating when giving feedback? British Journal of Educational Technology 40, no. 2: 306-15.

Duncan, N. 2007. 'Feed-forward': Improving students' use of tutors' comments. Assessment \& Evaluation in Higher Education 32, no. 3: 271-83.

Ecclestone, K., and J. Swann. 1999. Litigation and learning: Tensions in improving university lecturers' assessment practice. Assessment in Education: Principles, Policy and Practice 6, no. 3: 377-89.

Freeman, M., and J. McKenzie. 2002. SPARK, a confidential web-based template for selfand peer-assessment of student teamwork: Benefits of evaluating across different subjects. British Journal of Educational Technology 33, no. 5: 551-69.

Fulda, J.S. 2005. The ethical limitations of online grading systems. British Journal of Educational Technology 36, no. 3: 559-61.

Gibbs, G., and C. Simpson. 2004. Conditions under which assessment supports students' learning. Learning and Teaching in Higher Education 1: 3-31.

Gipps, C.V. 2005. What is the role for ICT-based assessment in universities? Studies in Higher Education 30, no. 2: 171-80.

Guardado, N., and L. Shi. 2007. ESL students' experiences of online peer feedback. Computers and Composition 24, no. 4: 443-61.

Handley, K., and B. Cox. 2007. Beyond model answers: Learners' perceptions of self-assessment materials in e-learning applications. ALT-J Research in Learning Technology 15, no. 1: 21-36.

Heinrich, E., J. Milne, A. Ramsay, and D. Morrison. 2009. Recommendations for the use of e-tools for improvements around assignment marking quality. Assessment \& Evaluation in Higher Education 34, no. 4: 469-79.

Hepplestone, S., and R. Mather. 2007. Meeting rising student expectations of online assignment submission and online feedback. In Proceedings of the 11th International Computer-Assisted Assessment Conference, July 10-11, ed. Farzana Khandia, 269-75. Loughborough: Learning and Teaching Development, Loughborough University.

Higgins, R., P. Hartley, and A. Skelton. 2002. The conscientious consumer: Reconsidering the role of assessment feedback in student learning. Studies in Higher Education 27, no. 1: $53-64$.

Higher Education Funding Council for England. 2007. 2007 teaching quality information data. Bristol: HEFCE. http://www.hefce.ac.uk/learning/nss/data/2007/.

Hornby, W. 2005. Dogs, stars, Rolls Royces and old double-decker buses: Efficiency and effectiveness in assessment. In: Enhancing practice: Reflections on assessment: Volume 1, 15-28. Gloucester: Quality Assurance Agency for Higher Education.

Hounsell, D. 2008. The trouble with feedback: New challenges, emerging strategies. TLA Interchange 2. http://www.tla.ed.ac.uk/interchange/spring2008/hounsell2.htm.

Hounsell, D., and N. Entwistle. 2007. Learning and teaching at university: The influence of subjects and settings. Teaching and Learning Research Briefings no. 31. London: ESRC Teaching and Learning Research Programme.

Irons, A. 2008. Enhancing learning through formative assessment and feedback. Abingdon: Routledge.

Li, L., X. Liu, and A.L. Steckelberg. 2010. Assessor or assessee: How student learning improves by giving and receiving peer feedback. British Journal of Educational Technology 41, no. 3: 525-36.

Loddington, S., K. Pond, N. Wilkinson, and P. Willmot. 2009. A case study of the development of WebPA: An online peer moderated marking tool. British Journal of Educational Technology 40, no. 2: 329-41. 
Maclellan, E. 2001. Assessment for learning: the differing perceptions of tutors and students. Assessment \& Evaluation in Higher Education 26, no. 4: 307-18.

McDowell, L., K. Sambell, V. Bazin, R. Penlington, D. Wakelin, H. Wickes, and J. Smailes. 2005. Assessment for learning: Current practice exemplars from the Centre for Excellence in Learning and Teaching. Newcastle: Centre for Excellence in Teaching and Learning, University of Northumbria.

Merry, S., and P. Orsmond. 2008. Students' attitudes to and usage of academic feedback provided via audio files. Bioscience Education 11. http://www.bioscience.heacademy.ac.uk/ journal/voll1/beej-11-3.aspx.

Middleton, A. 2009. Beyond podcasting: Creative approaches to designing educational audio. ALT-J Research in Learning Technology 17, no. 2: 143-55.

Miller, T. 2009. Formative computer-based assessment in higher education: The effectiveness of feedback in supporting student, learning. Assessment \& Evaluation in Higher Education 34, no. 2: 181-92.

Mutch, A. 2003. Exploring the practice of feedback to students. Active Learning in Higher Education 4, no. 24: 24-38.

Nesbit, P.L., and S. Burton. 2006. Student justice perceptions following assignment feedback. Assessment \& Evaluation in Higher Education 31, no. 6: 655-70.

Nicol, D. 2007. Improving assessment after the task. Re-Engineering Assessment Practices in Scottish Education (REAP) online resources. http://www.reap.ac.uk/nss/nssAfter02. html.

Nicol, D. 2009. Assessment for learner self-regulation: Enhancing achievement in the first year using learning technologies. Assessment \& Evaluation in Higher Education 34, no. 3: $335-52$.

Nicol, D.J., and D. Macfarlane-Dick. 2006. Formative assessment and self-regulated learning: A model and seven principles of good feedback practice. Studies in Higher Education 31, no. 2: 199-218.

Parkin, H.J., S. Hepplestone, G. Holden, B. Irwin, and L. Thorpe. Forthcoming A role for technology in enhancing student engagement with feedback. Assessment \& Evaluation in Higher Education.

Peat, M., and S. Franklin. 2002. Supporting student learning: The use of computer-based formative assessment modules. British Journal of Educational Technology 33, no. 5: 51523.

Plimmer, B., and P. Mason. 2006. A pen-based paperless environment for annotating and marking student assignments. In Proceedings of Seventh Australian User Interface Conference (AUIC2006), January 16-19, ed. Wayne Piekarski, 37-44. Darlinghurst, Australia: Australian Computer Society Inc.

Potts, D. 1992. Case study: You can't teach those things to rats. A case for neither grading nor failing students. Educational and Training Technology International 29, no. 4: 296309.

Poulous, A., and M.J. Mahony. 2007. Effectiveness of feedback: The students' perspective. Assessment \& Evaluation in Higher Education 33, no. 2: 143-54.

Price, M., and B. O'Donovan. 2008. Feedback - All that effort, but what is the effect? Paper presented at the EARLI/Northumbria Assessment Conference, August 27-29, in Potsdam, Germany.

Price, M., K. Handley, J. Millar, and B. O’Donovan. 2010. Feedback: All that effort, but what is the effect? Assessment \& Evaluation in Higher Education 35, no. 3: 277-89.

Ribchester, C., D. France, and A. Wheeler. 2007. Podcasting: A tool for enhancing feedback? Paper presented at the 4th Education in a Changing Environment International Conference 2007, September 12-14, in Salford, UK.

Rodway-Dyer, S., E. Dunne, and M. Newcombe, M. 2009. Audio and screen visual feedback to support student learning. In Proceedings of the 16th ALT-C International Conference, September 8-10, ed. Hugh Davies and Linda Creanor, 61-9. Oxford: Association for Learning Technology.

Rotheram, B. 2009. Sounds good: Quicker, better assessment using audio feedback. JISCfunded project. http://sites.google.com/site/soundsgooduk/downloads. 
Rowe, A.D., and L.N. Wood. 2007. What feedback do students want? Paper presented at the AARE 2007 International Educational Research Conference, November 25-29, in Fremantle, Australia.

Rust, C., B. O'Donovan, and M. Price. 2005. A social constructivist assessment process model: How the research literature shows us this could be best practice. Assessment \& Evaluation in Higher Education 30, no. 3: 231-40.

Sadler, D.R. 2010. Beyond feedback: Developing student capability in complex appraisal. Assessment \& Evaluation in Higher Education 35, no. 5: 535-50.

Tuzi, F. 2004. The impact of e-feedback on the revisions of L2 writers in an academic writing course. Computers and Composition 21, no. 2: 217-35.

Van den Boom, G., F. Paas, J.J.G. Van Merriënboer, and T. Van Gog. 2004. Reflection prompts and tutor feedback in a web-based learning environment: Effects on students' self-regulated learning competence. Computers in Human Behavior 20, no. 4: 551-67.

Weaver, M.R. 2006. Do students value feedback? Student perceptions of tutors' written responses. Assessment \& Evaluation in Higher Education 31, no. 3: 379-94.

Whitelock, D. 2009. Editorial: e-assessment: Developing new dialogues for the digital age. British Journal of Educational Technology 40, no. 2: 199-202.

Wojtas, O. 1998. Feedback? No, just give us the answers. Times Higher Education Supplement, September 25, 7.

Yorke, M. 2001. Formative assessment and its relevance to retention. Higher Education Research and Development 20, no. 2: 115-26. 